\title{
Frequency of hepatitis E and Hepatitis A virus in water sample collected from Faisalabad, Pakistan
}

\author{
Tahir Ahmad', Sadia Anjum', Najam-us-Sahar Sadaf Zaidi', Amjad Ali', Muhammad Waqas', \\ Muhammad Sohail Afzal' ${ }^{2}$, Najma Arshad ${ }^{3}$ \\ ${ }^{1}$ Atta-ur-Rahman School of Applied Biosciences, National University of Sciences and Technology, Islamabad, Pakistan \\ ${ }^{2}$ Department of Chemistry, School of Sciences, University of Management and Technology (UMT) Lahore, Pakistan \\ ${ }^{3}$ Department of Zoology, University of the Punjab, Lahore, Pakistan
}

Ahmad T, Anjum S, Zaidi NS, Ali A, Wagas M, Afzal MS, Arshad N. Frequency of hepatitis E and Hepatitis A virus in water sample collected from Faisalabad, Pakistan. Ann Agric Environ Med. 2015; 22(4): 661-664. doi: 10.5604/12321966.1185903

\begin{abstract}
Hepatitis E and Hepatitis A virus both are highly prevalent in Pakistan mainly present as a sporadic disease. The aim of the current study is to isolate and characterized the specific genotype of Hepatitis E virus from water bodies of Faisalabad, Pakistan. Drinking and sewage samples were qualitatively analyzed by using RT-PCR. HEV Genotype 1 strain was recovered from sewage water of Faisalabad. Prevalence of HEV and HAV in sewage water propose the possibility of gradual decline in the protection level of the circulated vaccine in the Pakistani population.
\end{abstract}

- Key words

Water, PCR, Public Health, HEV, HAV

\section{BACKGROUND}

Hepatitis $\mathrm{E}$ virus (HEV) infection is perhaps the most recurrent acute viral hepatitis $(\mathrm{VH})$ infection around the world. It is anticipated that one-third of the population living in developing countries has been infected with HEV [1]. Worldwide spread of HEV has been strongly associated with the socioeconomic status of the populations; and seroprevalence is reported highest in populations living in poor sanitation conditions. High endemic areas include Central and South East Asia with 20\% of anti-HEV seroprevalence among the general population of China, $45 \%$ in rural areas of Malaysia and 20\% in India [2, 3]. Both HEV and HAV are small non-enveloped single-stranded RNA viruses with higher stability in environment. HAV and HEV are mainly transmitted through the fecal-oral route; HAV is acquired primarily through close personal contact and food borne outbreaks, while most common route of transmission for $\mathrm{HEV}$ is probably food borne. HEV is acquired either through drinking water contaminated with feces from infected individuals or animals, or via intake of meat from infected animals [4, 5]. HAV has worldwide distribution, but epidemics of HAV are rare. HAV generally effects infants and young children but HEV affects older children and young adults [6]. The mortality rate of HEV is normally low $(<1 \%)$, however this infection could bear serious consequences for pregnant women; mortality rate among this group is reported up to $20-25 \%$ [7]. The severe course in pregnant women might result from hormonal and immunologic features of pregnancy [8]. Reduced expression of the progesterone receptor is predicted as one of the possible reason associated with fatal outcomes from hepatitis $\mathrm{E}$ in pregnant women [9]. HAV infection in infants and young children is mostly asymptomatic, however

Address for correspondence: Tahir Ahmad, Attu-ur-Rahman School of Applied Biosciences, National University of Sciences and Technology, Islamabad, Pakistan Email: baig42@gmail.com

Received: 09 January 2015; accepted: 14 April 2015 among adolescents and adults, travelers, homosexual men and injectable drug users HAV infection causes more-severe clinical disease including jaundice [10]. Acute HAV hepatitis during the third trimester of pregnancy is linked to a high risk of gestational complications (69\%) and is associated with preterm labor. There are handful of reports showing direct correlation between the gestational age and HAV infection; $\mathrm{HAV}$ is accountable for the early labor and associated fever and hypoalbuminemia are recommended as markers for a more hostile course of disease, leading to pregnancy complications, thus HAV assessment and maternal vaccination during prepregnancy evaluation is recommended in areas of the world in which susceptible adult populations exist [11].

Different HEV genotypes are prevalent around the globe. HEV isolates are divided into 4 genotypes and more than 24 subtypes [12]. HAV is divided into seven different genotypes (I-VII), which infect human (I-III) and simian (IV-V) [13]. HAV and HEV are an important public health concerns in Pakistan [14]. Previous reports from Pakistan indicate extensive diversity among HEV isolates SAR-55 (87-Pakistan-A), Abb-2B (88-Pakistan) and 87-Pakistan-B has been reported. All these three strains belong to HEV genotype 1 with $90 \%$ sequence homology $[15,16]$. To our knowledge, no HEV and HAV isolates has been characterized from Faisalabad, Pakistan to date. In this regards we collected 75 water samples from highly congested communities of the town. Our study reveals that genetic variations exist in different $\mathrm{HEV}$ strains however HEV-1 genotype is predominant in the population. The nucleotide sequence analysis revealed presence of genotype 1 of HAV.

\section{MATERIALS AND METHODS}

\section{Water samples}

Seventy five water samples were collected from May 2013 to October 2013 from Faisalabad, Pakistan. One liter surface water samples were collected; 10 samples from open ponds, 
20 samples from canals. Two liter tap water samples were collected; 20 samples from storage containers used for drinking and 20 samples from domestic uses in different communities. Physical parameters like temperature and $\mathrm{pH}$ were recorded. Samples were immediately transported in ice boxes to the laboratory for further processing.

\section{Virus concentration}

To flocculate the viruses, $\mathrm{pH}$ was adjusted to 3.5 with $1 \mathrm{~N} \mathrm{HCl}$ and then $0.0015 \mathrm{~N}$ aluminum chloride was added, stirred gently at room temperature for 30 minutes. The water samples were passed through negatively charged membrane filters $47 \mathrm{~mm}$ diameter, $0.45 \mu \mathrm{m}$ pore size (Millipore, USA). Membrane was wash with $0.14 \mathrm{M} \mathrm{NaCl}, \mathrm{pH} 3.5$, the viruses were eluted by adding $2.9 \%$ tryptose phosphate broth containing 6\%glycine, $\mathrm{pH}$ 9. Elutes were adjusted to $\mathrm{pH} 7-7.4$ with $4 \mathrm{~N} \mathrm{HCl}$ and were concentrated by using DNA concentrator.

\section{RNA extraction}

RNAs were extracted by using QIAmp viral RNA extraction Kit (QIAGEN, Switzerland).

\section{Primer designing}

There are two sets of primer (Tab.1) i.e primer set for 1-9 is designed from ORF2 and is used to distinguish between the four genotypes of HEV and primer set $10 \& 11$ is used for the detection of HAV from water samples.

Table 1. HEV primer set for genotypes (1-4) assessment: number of nucleotide (Nts) or size of each primer and nucleotide positions are shown in the table

\begin{tabular}{|c|c|c|c|c|}
\hline $\begin{array}{l}\text { Sr. } \\
\text { No }\end{array}$ & Name & Sequence $\left(5^{\prime}-3^{\prime}\right)$ & $\begin{array}{l}\text { Size } \\
\text { (Nts.) }\end{array}$ & $\begin{array}{c}\text { Nucleotide } \\
\text { Position }\end{array}$ \\
\hline 1 & HEV cDNA & CCGTCCTGGCCCTTCTCGACCA & 22 & $4066-4088$ \\
\hline 2 & HEV G1FP & CCCAGCGCCTITCGCTCACCGG & 22 & 1978- 2000 \\
\hline 3 & HEV G1RP & GAGCCCACCGCCAGGGCGGTGG & 23 & $2431-2454$ \\
\hline 4 & $\begin{array}{l}\text { HEV } \\
\text { G2 FP }\end{array}$ & CAGCGCCAGTCGGTTATTGGTA & 22 & $1981-2003$ \\
\hline 5 & $\begin{array}{l}\text { HEV } \\
\text { G2 RP }\end{array}$ & GCCCGCCACCAGGGCGGTGGCC & 22 & $2424-2446$ \\
\hline 6 & $\begin{array}{l}\text { HEV } \\
\text { G3 FP }\end{array}$ & CCAGCCTTCCTGAGCCTCCACC & 23 & $2324-2346$ \\
\hline 7 & $\begin{array}{l}\text { HEV } \\
\text { G3 RP }\end{array}$ & GCTCATCGCCGGGGCGGTGG & 20 & $2769-2789$ \\
\hline 8 & $\begin{array}{l}\text { HEV } \\
\text { G4 FP }\end{array}$ & $\begin{array}{l}\text { CCC CGG GTA ATC CTG TTA TTG } \\
\text { AGT CTG TTC }\end{array}$ & 30 & 2001-2031 \\
\hline 9 & $\begin{array}{l}\text { HEV } \\
\text { G4 RP }\end{array}$ & GGCCACCACCAGGGCGGTGGCCC & 23 & $2491-2514$ \\
\hline 10 & HAV FP & GTTITGCTCCTCTITATCATGCTATG & 26 & 2109-2135 \\
\hline 11 & HAV RP & GGAAATGTCTCAGGTACTITCTITG & 25 & $2330-2355$ \\
\hline
\end{tabular}

\section{PCR amplification and genotyping of HEV and HAV}

The extracted RNA was used to amplify HEV and HAV genome segment using specific primes as describe above. The RTPCR amplification was performed according to the program described previously [14].Sewage water samples were mainly tested for HAV. The temperature of water was in the range of 25 to $28^{\circ} \mathrm{C}$ and $\mathrm{pH}$ was in the range of $6.5-7.8$. Primer set 10-11 was used for the detection of HAV from water samples. Similar PCR program was used for HAV amplification as the product size of both were not vastly different.

\section{Polygenetic Analysis}

The PCR products of positive samples were run on $2 \%$ agarose gel prepared in $0.5 \times$ TBE buffer and purified were purified by gel purification kit (Invitrogen, USA) according to manufactures' protocol and were sequenced by DNA Genetic Analyzer (Beckman Coulter, USA) as described earlier [17]. The open reading frame (ORF2) of HEV sequences were retrieved from NCBI GeneBank considering genome from diverse population including Hetian, China, Ugih, Pakistan etc. Two of our sequences from Faisalabad district, Pakistan were analyzed by using CLC Sequence viewer version 7.5. The phylogenetic tree was then constructed by neighbor joining method. The boot strap value was set to 100 .

\section{RESULTS}

Specific PCR primers were used for the molecular detection of $\mathrm{HEV}$ and HAV from water samples. Our results revealed that HEV genotype 1 is most prevalent genotype in Faisalabad, Pakistan.

Sewage water samples were particularly tested for HAV. Only 3 out of 20 sewage water samples showed positive result for HAV. Both HEV and HAV showed negative results for tap water, but sewage water showed positive results both for $\mathrm{HEV}$ and HAV, which reflect prevalence of both viruses in the community. Positive samples appeared mostly from those areas which were thickly populated and belonged to poor communities (Fig.1). In order to explore the evolutionary relationship, HEV sequenced data were analyzed against several other HEV genotypes 1 sequences available in NCBI Gene data bank by using CLC Sequence Viewer 7.5 software package. Our results indicate presence of two separate clad (Clad $1 \& 2$ ) in the selected sequences (Fig. 2) interestingly

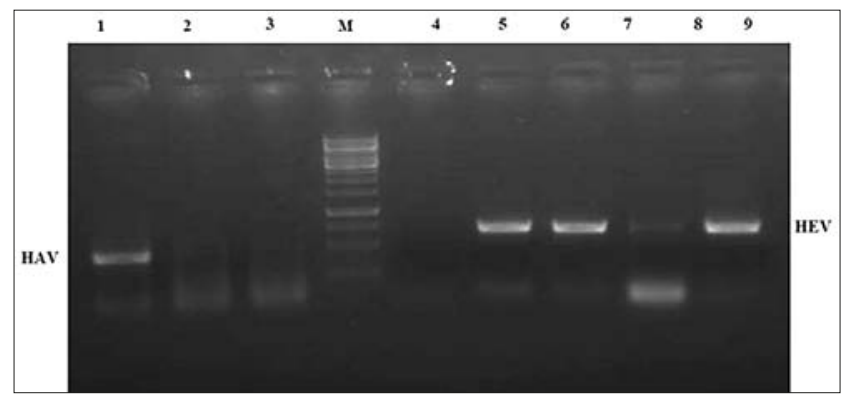

Figure 1. Amplification of HEV and HAV from sewage water sample of Faisalabad, Pakistan. Lane 1 to 2 showing 250bp of HAV bands, lane 3 and 4 shows negative control, lane 5 to 9 represents the HEV positive sample with $375 \mathrm{bp}$ amplification, Lane M showing $100 \mathrm{bp}$ molecular marker

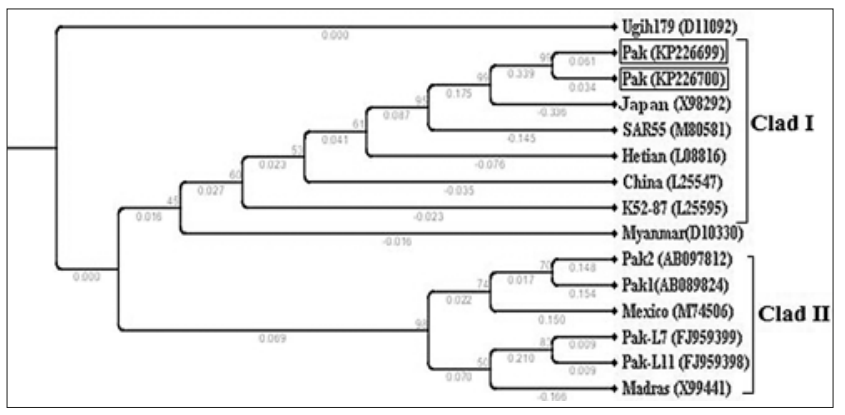

Figure 2. Rooted phylogenetic tree of HEV Genotype 1 (ORF2) was constructed using CLC sequencer viewer 7.5 by neighbor joining method. This phylogenetic tree based on partial sequence of HEV isolate form Faisalabad, Pakistan Accession number (KP226699, KP226700) and other representative sequences were retrieved from NCBI GeneBank. Bootstrap value was set to 100. 
two Pakistani HEV isolates previously reported from Lahore region were aligned on Clad 2 (Pak-L7 (FJ959399), Pak-L11 (FJ959398), while both sequences from present study clustered on Clad 1.

\section{DISCUSSION}

In Pakistan there are all types of hepatitis from A to E, with maximum morbidity in HEV and HAV and maximum mortality rate associated with HBV, HCV and HDV. The aim of this study was to evaluate the disease burden of HEV and HAV which can provide the road map for the policy makers in the underdeveloped country like Pakistan to make strategy for the prevention and control of this disease. HAV causes $50-60 \%$ acute hepatitis especially in children under less than 12 year of age. There is vaccine available for its prevention, two doses of vaccine are recommended for lifelong immunity, but its use is suggested for the visitor coming from endemic areas [18] and is not part of the routine vaccination. HEV is mainly asymptomatic, however HEV acquired in the late trimester of pregnancy is associated with high (30\%) maternal or fetal mortality [19].

PCR techniques is one of the most reliable and sensitive tool for the detection of HEV and HAV in water samples. Low density of virus in water makes it possible to improve the variety of concentration methods for the isolation of $\mathrm{HEV}$ and HAV from water sources. In present study, we adopted negatively charged membrane filters $(0.2$ to $0.45 \mu \mathrm{m}$ pore size) (Millipore, USA). Negatively charged membrane filter is one of the best and cost effective methods for the concentration of different viruses from the environmental samples [20].

This study reports prevalence of HEV and HAV in sewage water which was collected from the highly congested populated areas, most inhabitants of these areas belonged to low middle socioeconomic group. In these areas domestic sewage flowed though nearby unlined open water channels. When water pipe line are very close to sewage channels, due to poor drainage system there is always a possibility of cross contaminations resulting in the outbreak of these viruses in the adjacent communities since both viruses are transmitted though fecal-oral route [11]. None of the tap water sample was positive for these viruses but three sewage samples proved to be positive both for HEV and HAV and may still pose risk factor via direct contamination of food/water or hands.

HEV mostly affect adult population in Pakistan, all of small epidemics have been reported due to poor sanitary condition [14]. Out of 75 total samples only three sewage samples were found positive for $\mathrm{HEV}$ which belonged to genotype 1 . The phylogenetic analysis of the sequences as shown in Figure 2 clearly divided the studied sequences into Clad $1 \& 2$. Clad 1 consist of sequence from Asian origin, interestingly two previously reported Pakistani HEV isolates aligned on Clad 2 (Pak-L7 (FJ959399), Pak-L11 (FJ959398) [21]. Both isolates in the current study were retrieved from Faisalabad district, one of the biggest economic hub of Pakistan, belongs to HEV Genotype 1 are clustered on clad 1.These isolates are similar to SAR-55 (M80581) which is reported from geographically far areas from Faisalabad and are distinct from Pak-L7 (FJ959399) in clad 2; previously isolated from Lahore [21]. SAR-55 is formerly reported main endemic strain in the various regions of Pakistan; perhaps inter travel within these region might be the cause of HEV in Faisalabad district. Thus our results are in line with the previous reports which are clearly indicated by the phylogenetic tree (Fig. 2).

Another important finding in this study is the prevalence of HAV along with HEV. All of the surface water taken from canal and other domestic sources used for drinking were negative for HAV; however, out of 20 sewage water samples tested for HAV only three (15\%) were positive both for HEV and HAV (Fig. 1). This co existence is due to the common rout of transmission (fecal oral rout) along with the poor sanitary condition in the surrounding areas. Contaminated food and water supplies increase the chances of outbreak in the thickly populated low socioeconomic areas of Pakistan. HEV in Pakistan has remained at a stable nonexpanding stage from 1970 to the year 2005, followed by an explosive emergence of new HEV variants. There is stern need to be conscious about the dissemination of the variant strains to other areas of Pakistan may lead to fiery HEV outbreaks [22]. A recent Outbreak of Hepatitis-A causing hundreds of infected people in Swat was ascribed to poor hygiene in the Swat area. The source was attributed to a polluted stream running along the area that receives all sanitation lines throughout the Mingora Bazaar; possibly this stream had contaminated the ground water; the major source of drinking water used in the area [23]. Thus the sporadic occurrence of HEV and HAV suggest the existence of potential threat of HEV and HAV in Faisalabad area, particularly to inhabitants of highly populated areas.

\section{CONCLUSION}

To prevent the outbreak of water born diseases in surrounding communities especially in big cities, it is necessary to keep water supplies free from fecal contamination. Regular assessment of water in domestic use should be implemented along with an assessment of viral risk potential of sewage water. In Pakistan, there is no system available to track the quality of water particularly with reference to viral contaminations. Here we suggest a regular water monitoring system for public health safety to avoid any out breaks in future.

\section{Acknowledgment}

I am highly thankful to National university of Sciences and Technology for providing the funds. I am also thankful to Dr. Najma Arshad (Assistant Professor, Punjab University, and Lahore) for the overall guidance during this manuscript.

\section{REFERENCES}

1. Purcell RH ESPITH, Lemon S, Zuckerman AJ,. Viral hepatitis. 3rd edn ed: Blackwell Publishing; 2005. p.635-45.

2. Chandra V, Taneja S, Kalia M, Jameel S. Molecular biology and pathogenesis of hepatitis E virus. J Biosci. 2008; 33(4): 451-64.

3. Das K, Agarwal A, Andrew R, Frösner G, Kar P. Role of hepatitis $\mathrm{E}$ and other hepatotropic virus in aetiology of sporadic acute viral hepatitis: a hospital based study from urban Delhi. Eur J Epidemiol. 2000; 16(10): 937-40.

4. Atkinson W, Wolfe S, Hamborsky J. Centers for Disease Control and Prevention Epidemiology and Prevention of Vaccine-preventable Diseases, “Pink Book,". Washington, DC: Public Health Foundation; 2011.

5. Bihl F, Negro F. Hepatitis E virus: a zoonosis adapting to humans. J Antimicrob Chemother. 2010; 65(5): 817-21. 
6. Traoré KA, Rouamba H, Nébié Y, Sanou M, Traoré AS, Barro N, et al. Seroprevalence of fecal-oral transmitted hepatitis A and E virus antibodies in Burkina Faso. PloS one. 2012; 7(10): e48125.

7. Purcell R, Emerson S. Hepatitis E: an emerging awareness of an old disease. J Hepatol. 2008; 48(3): 494-503.

8. Navaneethan U, Al Mohajer M, Shata MT. Hepatitis E and pregnancy: understanding the pathogenesis. Liver International. 2008; 28(9): 1190-9.

9. Bose PD, Das BC, Kumar A, Gondal R, Kumar D, Kar P. High viral load and deregulation of the progesterone receptor signaling pathway: association with hepatitis E-related poor pregnancy outcome. J Hepatol. 2011; 54(6): 1107-13

10. Jacobsen KH, Koopman JS. Declining hepatitis A seroprevalence: a global review and analysis. Epidemiol Infect. 2004; 132(06): 1005-22.

11. Elinav E, Ben-Dov IZ, Shapira Y, Daudi N, Adler R, Shouval D, et al Acute hepatitis A infection in pregnancy is associated with high rates of gestational complications and preterm labor. Gastroenterol. 2006; 130(4): 1129-34.

12. Lu L, Li C, Hagedorn CH. Phylogenetic analysis of global hepatitis E virus sequences: genetic diversity, subtypes and zoonosis. Rev Med Virol. 2006; 16(1): 5-36.

13. Hussain Z, Das BC, Husain SA, Asim M, Chattopadhyay S, Malik A, et al. Hepatitis A viral genotypes and clinical relevance: Clinical and molecular characterization of hepatitis A virus isolates from northern India. Hepatol Res. 2005; 32(1): 16-24.

14. Ahmad T, Waheed Y, Tahir S, Safi SZ, Fatima K, Afzal MS, et al. Frequency of HEV contamination in sewerage waters in Pakistan. J Infect Dev Ctries. 2010; 4(12): 842-5.

15. Bosan A, Qureshi H, Bile KM, Ahmad I, Hafiz R. A review of hepatitis viral infections in Pakistan. J Pak Med Assoc. 2010; 60(12): 1045-58.
16. Panda SK, Thakral D, Rehman S. Hepatitis E virus. Rev Med Virol. 2007; 17(3): 151-80

17. Waheed Y, Tahir S, Ahmad T, Qadri I. Sequence comparison and phylogenetic analysis of core gene of hepatitis $\mathrm{C}$ virus from Pakistani population. Afr J Biotechnol. 2010; 9(29): 4561-7.

18. Butt FA, Amin I, Idrees M, Iqbal M. Hepatitis delta virus genotype-1 alone cocirculates with hepatitis B virus genotypes A and D in Pakistan. Eur J Gastroenterol Hepatol. 2014; 26(3): 319-24. Epub 2013/10/17. doi: 10.1097/MEG.0000000000000007. PubMed PMID: 24129252.

19. Oncu S, Okyay P, Ertug S, Sakarya S. Prevalence and risk factors for HEV infection in pregnant women. Med Sci Monit. 2006; 12(1): CR36-9. Epub 2005/12/22. PubMed PMID: 16369469.

20. Kittigul L, Ekchaloemkiet S, Utrarachkij F, Siripanichgon K, Sujirarat $\mathrm{D}$, Pungchitton $\mathrm{S}$, et al. An efficient virus concentration method and RT-nested PCR for detection of rotaviruses in environmental water samples. J Virol Methods. 2005; 124(1-2): 117-22. Epub 2005/01/25. doi: 10.1016/j.jviromet.2004.11.013. PubMed PMID: 15664059.

21. Iqbal T, Idrees M, Ali L, Hussain A, Ali M, Butt S, et al. Isolation and characterization of two new hepatitis E virus genotype 1 strains from two mini-outbreaks in Lahore, Pakistan. Virol J. 2011; 8(1): 94.

22. Khan A, Tanaka Y, Kurbanov F, Elkady A, Abbas Z, Azam Z, et al. Investigating an outbreak of acute viral hepatitis caused by hepatitis $\mathrm{E}$ virus variants in Karachi, South Pakistan. Journal of medical virology. 2011;83(4):622-9.

23. Malik MA, Azam EM, Saboor A. Water Quality Status of Upper KPK and Northern Areas of Pakistan. Pakistan Council of Research in Water Resources (PCRWR), Water Resources Research Centre, Peshawar, Pakistan; 2010. 